Istanbul Finance Congress, November 1-2, 2018, Istanbul, Turkey.

\title{
SOCIALLY RESPONSIBLE FINANCE: A CURRENT LITERATURE SURVEY ON THE CONCEPTS AND THE APPROACHES
}

\author{
DOI: 10.17261/Pressacademia.2018.980 \\ PAP-IFC- V.8-2018(12)-p.51-55
}

\section{Narman Kuzucu}

Beykent University, Faculty of Economics and Administrative Sciences, Department of Business, Maslak Campus, Istanbul, Turkey. narmankuzucu@beykent.edu.tr, ORCID: 0000-0003-2265-6492

\author{
To cite this document \\ Kuzucu, N. (2018). Socially responsible finance: A current literature survey on the concepts and the approaches. PressAcademia Procedia \\ (PAP), V.8, p.51-55 \\ Permanent link to this document: http://doi.org/10.17261/Pressacademia.2018.980 \\ Copyright: Published by PressAcademia and limited licenced re-use rights only.
}

\section{ABSTRACT}

Purpose - Socially responsible finance has emerged as a growing area of interest. In this study, the objective is to distinguish the concepts such as responsible investing, impact investments, environmental, social and governance criteria investments and to discuss the recent approaches.

Methodology - We surveyed the current literature by reviewing published academic studies and reports.

Findings- Social finance is still growing and developing. Various international organizations and networks have proceeded pioneering works. While the conceptual framework has been growing recently, social impact investments have been the area in which the most important developments occurred.

Conclusion- In the wake of the Global Financial Crisis, finance, which aims to maximize return and individual wealth, is criticized severely. A perception, that prioritizes social impact, sustainability and corporate governance rather than individual benefit, has been advancing theoretically and practically. In this context, it is required to design new approaches and new financial instruments, which address various social needs. Furthermore, new regulations should be adopted.

Keywords: ESG criteria, impact investments, social finance, socially responsible investing

JEL Codes: G11, G38, G39

\section{SOSYAL SORUMLU FINANS: KAVRAMLAR VE YAKLAŞIMLAR ÜZERINE GÜNCEL BíR LITERATÜR TARAMASI}

\section{ÖZET}

Amaç- Sosyal sorumlu finans, gittikçe büyüyen bir ilginin olduğu alan olarak karşımıza çıkmaktadır. Bu çalışmada, teoride ve pratik alanda gelişmekte olan sosyal finans alanında öne çıkan sorumlu yatırım, etki yatırımları, çevresel, sosyal ve yönetişimsel kriterlere uygun yatırımlar gibi konuların ayrımını yapmak, kavram ve yaklaşımları araştırmak amaçlanmıştır.

Yöntem- Güncel bir literatür taraması yapılarak, ilgili alanda yayınlanmış akademik çalışmalar ve raporlar incelenmiştir.

Bulgular- Sosyal finans, halen gelişimini sürdüren ve büyümekte olan bir sahadır. Çeşitli uluslararası örgütlerin küresel ve bölgesel düzeyde öncül çalışmalar yaptığı belirlenmiştir. Yakın zamanda kavramsal çerçeve gelişirken, sosyal finansta en önemli gelişmenin olduğu alan, sosyal etki yatırımları olmuştur.

Sonuç- Özellikle küresel finansal krizden sonra, getiri maksimizasyonu ve bireylerin servetinin artırılmasını hedefleyen finans, pek çok eleştiriye uğramıştır. Bireysel getiriden ziyade, toplumsal etki, sürdürülebilirlik ve kurumsal yönetişimi önceleyen bir finansal anlayışın hem teorik alanda hem de uygulamada gelişmekte olduğu görülmektedir. Bu bağlamda, farklı sosyal ihtiyaçlara hitap eden yeni yaklaşımların ve yeni ürünlerin tasarlanmasına, düzenlemelerin geliştirilmesine ihtiyaç vardır.

Anahtar Kelimeler: ÇSY kriterleri, etki yatırımları, sosyal sorumlu finans, sosyal sorumlu yatırım JEL Kodları: G11, G38, G39

\section{GiRiş}

Sosyal sorumlu finans, gittikçe büyüyen bir ilginin olduğu alan olarak karşımıza çıkmaktadır. Bu çalışmada, teoride ve pratik alanda gelişmekte olan sosyal finans alanında öne çıkan sorumlu finans, etki yatırımları, çevresel, sosyal ve yönetişim kriterleri gibi konuların ayrımını yapmak, söz konusu alanlara ilişkin akademik literatür ve pratisyen raporlarını tarayarak yakın zamanda ortaya çıkan ve gelişen 
yaklaşımları araştırmak amaçlanmıştır. Bu amaçla, güncel bir literatür taraması yapılarak, ilgili alanda yayınlanmış akademik çalışmalar ile uygulamacı ve araştırmacı kurum raporları incelenmiştir.

Yakın zamanda ivme kazanarak gelişimini hızlandıran alanda küresel terminoloji İngilizce olduğundan, bu çalışmada kavramların İngilizce orijinallerine ve çoğu zaman tarafımızca getirilen Türkçe karşılıklarına beraberce yer verilmiştir. Genel olarak "Sosyal Sorumlu Finans" (SSF) olarak adlandırılan ve gelişmekte olan finans alanı pek çok adlarla anılmaktadır. Bunların öne çıkanlarını yaygın olarak kullanılan İngilizce terimler ile Türkçe karşılıklarını şöyle sıralayabiliriz:

- $\quad$ social finance / sosyal finans,

- (socially) responsible investments / (sosyal) sorumlu yatırımlar,

- ethical investing / etik yatırımlar,

- green investing / yeşil yatırımlar,

- (social) impact investments / (sosyal) etki yatırımları.

Bu kavramların yanı sıra mikro finans, sosyal bankacılık, kitle fonlaması, sosyal işletmecilik, sosyal girişimcilik, çevresel, sosyal ve yönetişimsel kriterler gibi kavramlar sosyal finans ile yakından ilişkilidir.

Çalışmamızın takip eden ikinci bölümünde sosyal sorumlu yatırımların ortaya çıkışına ve tarihsel süreçte gelişimine kısaca yer verilmiştir. Üçüncü bölümde, sosyal sorumlu yatırımın tanımı ve kapsamı tartışılmıştır. Bu çerçevede sosyal sorumlu yatırım kavramının evrimine, ESG yatırımları, etki yatırımları gibi sorumlu yatırım türlerine değinilmiştir. Son bölümde, çalışmada elde edilen bulguların genel bir değerlendirmesi yapılmıştır.

\section{SOSYAL SORUMLU YATIRIMIN GELIŞIMI}

Sosyal sorumlu yatırımın (SSY) kökenleri, orta çağa kadar götürülebilmektedir. Avrupa'da 15. yüzyılda, Franciscan hareketi tarafından İtalya'da kurulan ve mensuplarına finansal destekler sağlayan Monti di Pietà, örnek olarak gösterilebilir. Daha sonraki zamanlarda kredi birliklerinin ve kooperatif bankalarının da benzer işlevleri olduğu, dezavantajlı kesimlere ve üyelerine finansal hizmetler sunmak için kuruldukları bilinmektedir (Chiappini, 2017, s.20).

Amerika'da ise SSY'nin ilk örnekleri, 18. yüzyılda bazı dini grupların, bağış fonlarının köle ticaretinde kullanılmasına karşı çıktığı sömürge döneminde görülmektedir. 1960 ve 70'lerde ise sorumlu yatırım anlayışının dini çerçeveden çıkıp, Vietnam Savaşı ve Güney Afrika'daki ırk ayrımcılığı gibi sosyal ve siyasal olayların da etkisiyle, daha protest bir çerçevede, toplumsal amaçlara yönelik bir yatırım şekli olduğunu görmekteyiz (Commonfund Institute, 2013)

Birleşmiş Milletler, 2006 yılında "Çevresel, Sosyal ve Yönetişimsel" (ÇSY) kriterler ile yatırım performansının ilişkisini formüle ederek, yatırımcıların gönüllü olarak uyulabileceği Sorumlu Yatırım IIlkelerini (Principles for Responsible Investment / UN PRI) yürürlüğe koymuştur. Birleşmiş Milletler Sorumlu Yatırım ilkeleri, yatırımcıların edilgen bir tutumla, zayıf çSY kayıtlarına sahip şirketlere yatırım yapmasını önlemekten ziyade, yatırım yapılacak şirket veya varlıkların ÇSY öğelerinin, belirli bir portföyün yatırım performansına katkısı ölçüsünde değerlendirilmesini önermektedir. Buna göre, ÇSY kriterlerinin yatırımların seçimi sürecindeki etkisi dinamik olmalıdır. ÇSY kriterleri dikkate alınırken, aynı zamanda farklı şirketler, sektörler, bölgeler incelenerek geleneksel yatırım analizi esaslarına uygun olarak değerlendirme yapılmalıdır (Commonfund Institute, 2013; UN PRI, 2016)

Birleşmiş Milletler tarafından Sorumlu Yatırım İlkelerinin yayınlanmasıyla, ÇSY kriterlerinin çerçevesi belirlenmiştir. 2013 yılına gelindiğinde pek çok finans kurumu ÇSY kriterlerini entegre ederek, sadece Avrupa Birliği'nde 1,9 trilyon Euro'nun üzerinde fonu yönetiyordu. 2015 yılı itibariyle bu rakam, iki yılda toplam \% 40’a yakın bir büyümeyle 2,6 trilyon Euro'nun üzerine çıkmıştır (Eurosif, 2016).

İlk sosyal hisse senedi borsası, Londra'da 2013 yılında Sosyal Hisse Senedi Borsası (Social Stock Exchange / SSX) adı altında kuruldu. Söz konusu borsanın lisanslı işletmecisi, İngiltere'nin önemli etki yatırım aktörlerinden olan Etki Yatırım Ağı (Impact Investment Network) adlı kuruluştur. Anılan borsada, 2018 yılı itibariyle 50 kadar şirket işlem görmektedir. Bir diğer sosyal borsa, özellikle kadının toplumda güçlendirilmesi ve dezavantajlı topluluklara hizmet edilmesi konularında faaliyetleriyle öne çıkan, Singapur orijinli Impact Investment Asia (Asia IIX) adlı etki yatırımı kurumu ve Morityus Borsası tarafından Morityus'da kuruldu (Chiappini, 2017, s.28; Drexler \& Noble, 2013).

2013 yılında, İngiltere'nin başkanlığındaki G8 zirvesinde kurulan Sosyal Etki Yatırım Özel Görev Komitesi (SıIT) tarafından sosyal etki yatırımlarının geliştirilmesi amacıyla çalışmalar yürütüldü. Bu çalışmaların sonucu olarak, 2014 yılında bir dizi tavsiye raporları yayınlandı (SIIT, 2014a, 2014b, 2014c).

Günümüzde sosyal sorumlu yatırım yapan ya da özellikle bu alana odaklanmış pek çok kurum ve bu kurumların oluşturduğu ağlar bulunmaktadır. Bunların en önemlilerinden olan Küresel Etki Yatırım Ağı (Global Impact Investing Network / GIIN), sosyal sorumlu yatırımların büyüklüğünün ve etkinliğinin artırılmasına küresel olarak öncülük eden kar amaçlı olmayan bir kuruluştur. Kuruluş, vizyonunu şu şekilde açıklamaktadır: "Vizyonumuz, finansal pazarların toplumun tüm üyelerine hizmet ettiği ve finansın küresel toplumun sosyal ve çevresel meselelerinin çözülmesinde merkezî rol oynadığı bir dünyaya dairdir. Böyle bir gelecekte yatırımcılar; güçlü toplumlar, sağııkı bir çevre ve bütün insanlar için sürdürülebilir bir gelecek inşası için, tüm kararlarında "etki" değerlendirmesinde bulunurlar" (GIIN, 2018).

Sosyal sorumlu yatırım pazarı her geçen yıl büyümekte ve yeni araç geliştirmeleri devam etmektedir. Son on yıldaki yıllık ortalama büyüme \%18 gibi dikkat çekici bir orandır. Varlıkların toplam büyüklüğü, 2016 başı itibariyle yaklaşık 23 trilyon USD olduğu kaydedilmektedir. Söz konusu varlıkların \%58'i Avrupa, \%38'i ABD'de bulunmaktadır (US SIF, 2017). 


\section{SOSYAL SORUMLU YATIRIMIN TANIMI VE KAPSAMI}

SSF, finans yoluyla pozitif sosyal etki yaratmaya çalışır. Pozitif sosyal etki ise yatırımın toplum, çevre ve sürdürülebilir kalkınma üzerindeki etkisidir. Söz konusu etki; krediler, yatırımlar, mikrofinans gibi hizmetler ve finansal ürünlerle oluşturulmaya çalışılır (Weber \& Duan, 2012, s.161). SSY, finansal getiri elde etmek ve aynı zamanda pozitif sosyal etki yaratmak için ÇSY kriterlerini kullanırlar (US SIF, 2016).

SSY, kişisel değerler ve toplumsal kaygıları, yatırım kararlarıyla bütünleştirir. Bu amaçla yatırımcılar; yatırım alternatiflerini, faaliyetleri veya ürünleri sosyal sorumluluk ölçülerine uygun olan işletme ve şirketlerle sınırlandırırlar (Baker \& Nofsinger, 2012, s.3; Bollen, 2007). Sosyal finansın finansal kaynak sağladığı alanların başlıcaları özetle şunlardır; fakirlik ve açlıkla mücadele, finansal kaynaklara erişimi sınırlı, dezavantajlı kesimlerin sosyal ihtiyaçlarının karşılanması, çevresel sorunlar ve sosyal girişimcilik.

\subsection{Sosyal Yatırımlarda Kullanılan Belirleme Yöntemi: İzleme}

Sosyal sorumlu yatırımcıların hangi alanlara ya da hangi varlıklara yatırım yapacağını belirleyebilmek amacıyla izleme yapmak gereklidir. İzleme (screening), bireysel ve kurumsal yatırımcıların yatırım alanlarını seçerken bir tür filtreleme ve seçim kıstasları kullanmasını ifade etmektedir. İzleme, iki türlü olabilmektedir. Bunlar, negatif izleme ve pozitif izleme yöntemleridir.

i) Negatif izleme: Sosyal sorumlu yatırımcıların duyarlılık taşıdığı bir takım sosyal, etik veya dini değerlere aykırı alanlara yatırım yapılmamasıdır. Bu alanlarda faaliyet gösteren ya da söz konusu değerlere aykırı hareket eden işletmeler yatııım listesinden çıkarılır. Sağlığa zararlı ya da günah kabul edilen tütün, alkol, kumar gibi alanlarda faaliyeti olan işletmelere yatırım yapılmaması ya da çevreye zehirli atık bırakan, insan hakları ihlallerine karışan firmaların yatırım portföyünden çıkarılması verilebilecek örneklerdir.

ii) Pozitif İleme: ÇSY kriterlerine göre sınıfında en iyi uygulamalara yer veren işletmelere yatırım yapılmasını ifade eder. Örneğin, geri dönüşüm konusunda en iyi uygulamalara yer veren işletmelere yatırım yapılması ya da şeffaflık, paydaş hakları konusunda duyarlı işletmelerin yatırım için seçilmesi pozitif izleme yönteminin kullanılmasıdır (Commonfund Institute, 2013; Fullwiler, 2016)

\subsection{Geleneksel Sosyal Sorumlu Yatırımdan ÇSY Yatırımlarına}

Yakın zamanlara kadar terminolojik kullanımda, SSY ile ÇSY kriterlerine uygun yatırım kavramları arasında fark yokmuş gibi görünse de günümüzde, bu iki yatırım şekli arasında bir farklılaşma bulunmaktadır.

SSY, etik değerlere göre yönlendirilen ve negatif izleme içeren yatırımları ifade etmektedir. SSY'da etik değerler ve kriterler sübjektif olduğundan, yatırımcılara göre değişiklik gösterebilmektedir. Ancak ÇSY yatırımlarında odak noktası, yüksek yatırım potansiyeli bulunan şirketlerin sürdürülebilirlik konusundaki performanslarıdır. Buna göre belirli yatırımlar negatif izlemeye alınmamakta, fakat ÇSY kriterleri dikkate alınarak bir sıralama veya derecelendirmeye tabi tutulmaktadırlar. Yatırım kararı verilirken yüksek sıralamalı şirketler öncelikli değerlendirilmektedir. ÇSY kriterleri, SSY ile karşılaştırıldığında evrensel bir yaklaşımı temsil etmektedir (Commonfund Institute, 2018; Drexler and Noble, 2013). O'Donohoe vd.'ne göre; SSY, olumsuz etkiyi en aza indirmeyi amaçlayan yatırımlarken, ÇSY yatırımları ise proaktif biçimde olumlu sosyal ve çevresel etkiler yaratır (O'Donohoe vd., 2010, s.14).

Literatürde SSY ve ÇSY yatırımlarının farklı anlamlarda kullanıldığı görülmektedir. SSY, daha genel ve sorumluluk kavramının yatırımcıya göre değiştiği sübjektif bir anlam taşırken, ÇSY yatırımları sorumluluk ölçütlerinin çevresel, sosyal ve yönetişimsel olarak somutlaştırıldığı, bununla birlikte bu alanlarda olumlu bir etki yaratmak için aktif bir tutumun izlendiği yatırım şeklidir. Buna göre, SSY daha çok negatif izleme kullanırken, ÇSY yatırımları pozitif izlemeyi benimsemektedir.

\subsection{Sosyal Etki Yatırımları (Impact Investments)}

Sosyal etki yatırımlarını, SSY ve ÇSY yatırımların yanı sıra ayrı bir sosyal yatırım tanımı veya türü olarak sayabiliriz. Etki yatırımları adı, ilk defa Italya'daki Rockefeller Merkezinde 2007 yılında bir araya gelen, finansal getiriden çok sosyal getiriye odaklanan uygulamacılar tarafından kullanılmıştır (Harji \& Jackson, 2012). Etki yatırımları, sosyal sorumlu yatırımların günümüzde ulaştığı en güncel, aktif ve objektif anlamı ifade etmektedir. Zira meydana getirilen etkinin ölçülerek, performansın belirlenmeye çalışılması sorumlu finansta yeni bir yaklaşımdır.

O’Donohoe vd.'ne göre (2010), etki yatırımları, finansal getirinin ötesinde pozitif sosyal etki yaratmak amacıyla yapılan yatırımlardır. Buna göre, bu tür yatırımlar, finansal risk ve getiriye ek olarak, sosyal ve çevresel performansın da yönetilmesini gerektirirler (Weber \& Duan, 2012, s.165). Küresel Etki Yatırımı Ağı'nın etki yatırımları tanımı şu şekildedir: Finansal bir getirinin yanı sıra ölçülebilir sosyal ve çevresel etki yaratmak amacıyla çeşitli şirket, kuruluş ve fonlara yapılan yatırımlardır (GIIN, 2018).

Etki yatırımları dört temel karakteristik özelliğe sahiptir:

- İsteklilik: Bir yatırımcının yapılan yatırım yoluyla bir pozitif sosyal veya çevresel etki meydana gelmesi konusunda istekli ve niyetli olması.

- Getiri beklentisi olan yatırım: Etki yatırımlarının az miktarda bile olsa finansal getiri sağlaması beklenir.

- Getiri beklentisine göre farklı varlık türleri: Etki yatıııları, -piyasanın altındaki bir orandan riske göre düzeltilmiş piyasa oranına kadar- belirli bir düzeyde finansal getiri hedeflerler. Buna göre, yatırım yapılacak varlıklar, finansal getirisi olan varlıklar olmalıdır.

- Etkinin ölçümü: Etki yatırımının ayırıcı özelliği; şeffaflık ve hesap verilebilirliğin sağlanarak, yapılan yatırımların sosyal ve çevresel performansının ve ilerlemesinin ölçülmesi ile raporlanmasının yatırımcının sorumluluğunda olmasıdır (GIIN, 2018).

Höchstädter ve Scheck (2015, s.456), hem akademik çalışmaları hem de uygulamacıların yayınlarını inceleyerek, etki yatırımlarının SSY'nın ötesine geçmiş bir yatırım biçimi olduğunu savunmuşlardır. SSY ve etki yatırımları arasında şu iki unsurun farklılık gösterdiğini belirlemişlerdir. 
- Yatırımın büyüklüğ̈̈: SSY, genellikle daha büyük ölçekte kurumlara yatırım yapmayı hedeflerken, etki yatırımları daha küçük ölçekli yatırımları tercih eder.

- Yatırımın mahiyeti: Sorumlu yatırımcılar, ikinci el piyasada alınıp satılabilen hisse senedi, tahvil gibi menkul kıymetleri ve fonları kullanırken, etki yatırımcıları doğrudan borç verme ya da özkaynağa katılma (ortak olma) yoluyla kuruluşların finansmanını sağlarlar.

\subsection{Mevzuat Düzenleme İhtiyacı}

Çalışmamızın odağında olmamakla birlikte, sosyal sorumlu yatırım piyasaları ve yatırım araçlarına yönelik yasal düzenlemeler hakkında kısa bir bilgilendirme yapmak uygun olacaktır. Yeni yatırım araçlarının ve yöntemlerinin geliştirildiği sosyal finans alanında yasal düzenlemeler yapılması kaçınılmazdır. Bazı ülkelerin bu alanda sınırlı da olsa belirli finansal araçlar için düzenlemeler yaptığı görülmektedir. Örneğin, İtalya mikro kredi uygulamaları için 2010 yılında yasal mevzuat hazırlamıştır. Nispeten yeni bir yöntem olan kitle fonlaması için de pek çok ülke düzenleme yapma imkanlarını aramaktadır (Addis, 2015).

ABD'de emeklilik fonları için konvansiyonel yatırım fonlarının yanı sıra, katılımcılara sosyal sorumlu alternatifler sunulmaktadır. Böylece bireysel yatırımcılara tasarruf ve emeklilik birikimlerini sosyal sorumlu yatırım fonlarında değerlendirme imkanı verilmektedir (Chiappini, 2017, s.29). Bunu, Türkiye'deki bireysel emeklilik sistemindeki bireysel yatırımcılara sağlanan faizsiz katılım bankacılığı alternatifine benzetmek mümkündür. İskandinav ülkelerinde de yaygın olan sosyal sorumlu emeklilik fonlarıyla bireysel yatırımcı, emeklilik planı kapsamında tasarruf yaparken, aynı zamanda topluma değer katma imkanı bulabilmektedir.

Sosyal Etki Yatırım Özel Görev Komitesi, sosyal ve çevresel amaçları olan etki yatırımları için, hükümetlere bu tür yatırımlar önündeki potansiyel engellerin kaldırılması ve kolaylaştırılması için önerilerde bulundu (SIIT, 2014b).

ABD'de "B Lab" adında kar amaçlı olmayan bir kuruluş, 'fayda şirketi' (benefit corporation veya kısaca B Corp) adıyla yeni bir şirket türünün yasal olarak kabul edilmesi konusunda çaba göstermektedir. ABD eyaletlerinin büyük bir kısmı bir takım farklılıklarla söz konusu öneriyi kabul etmiştir. Sorumluluk ve faaliyet alanı sosyal etki yatırımları olması öngörülen ve bu alanda şeffaflık ve hesap verilebilirliği artırması amaçlanan 'fayda şirketi', İtalya ve Avustralya yasal mevzuatına da girmiştir (B Lab, 2018; Chiappini, 2017, s.29-30)

\section{SONUÇ}

Özellikle Küresel Finansal Krizden sonra, getiri maksimizasyonu ve bireylerin servetinin artırılmasını hedefleyen finans, pek çok eleştiriye uğramıştır. Bireysel getiriden ziyade, toplumsal etki, sürdürülebilirlik ve kurumsal yönetişimi önceleyen bir finansal anlayışın hem teorik alanda hem de uygulamada gelişmekte olduğu görülmektedir. Buna paralel olarak, farklı sosyal ihtiyaçlara hitap eden yeni yaklaşımların ve yeni ürünlerin tasarlanmasına, düzenlemelerin geliştirilmesine ve teşviklerin sağlanmasına ihtiyaç vardır. Bir paradigma değişiminden söz etmek aşırı iyimserlik olsa da tüm toplumun faydasını gözeten, çevre gibi konularda hassasiyet gözeten, sürdürülebilirliği dikkate alan bir finans ve yatırım modelinin gelişmesi, sosyal girişimciliğin ve sivil toplumun da gelişmesine katkıda bulunmaktadır.

\section{KAYNAKLAR}

Addis, R. (2015). The roles of government policy in social finance. (Ed. A. Nicholls, R. Paton \& J. Emerson) Social Finance içinde, $383-459$. Oxford: Oxford University Press.

Baker, H. K. \& Nofsinger, J. R. (2012). Socially Responsible Finance and Investing. New Jersey: Wiley.

B Lab. (2018). GIIRS. (Erişim tarihi: 18.10.2018) http://b-analytics.net/giirs-funds.

B Lab. (2018). About B-Corps. (Erişim tarihi: 15.10.2018) https://www.bcorporation.net/what-are-b-corps.

Bollen, N. P. B. (2007). Mutual fund attributes and investor behavior. Journal of Financial and Quantitative Analysis 42(3): 683-708.

Chiappini, H. (2017). Social Impact Funds: Definition, Assessment and Performance. Palgrave Studies in Impact Finance, Springer.

Commonfund Institute, (2013). From SRI to ESG: The changing world of responsible investing. (Erişim tarihi: 10.09.2018) http://info.commonfund.org/from-sri-to-esg-the-changing-world-of-responsible-investing.

Commonfund Institute, (2018). The challenges of terminology. (Erişim tarihi: 10.09.2018) https://www.commonfund.org/newsresearch/blog/what-are-the-differences-between-sri-and-esg/.

Drexler, M. \& Noble, A. (2013). From the margin to the mainstream: Assessment of the impact investment sector and opportunities to engage mainstream investors. Cologny: World Economic Forum.

http://www3.weforum.org/docs/WEF II FromMarginsMainstream Report_2013.pdf.

Eurosif. (2016). European SRI study 2016. (Erişim tarihi: 10.09.2018) http://www.eurosif.org/wp-content/uploads/2016/11/SRI-study2016-HR.pdf

Fullweiler, S. (2016). Sustainable finance. (Ed. O. M. Lehner) Routledge Handbook of Social and Sustainable Finance içinde, 17-34. New York: Routledge.

GIIN. (2018). What you need to know about impact investing. (Erişim tarihi: 10.09.2018) https://thegiin.org/impact-investing/need-toknow/. 
GRI. (2018). The GRI standard. (Erişim tarihi: 18.10.2018) https://www.globalreporting.org/information/sustainability-reporting/Pages/gristandards.aspx.

Harji, K. \& Jackson, E.T. (2012). Accelerating impact: Achievements, challenges and what's next in building the impact investing industry. New York: The Rockefeller Foundation. (Erişim tarihi: 21.09.2018) https://assets.rockefellerfoundation.org/app/uploads/20120707215852/Accelerating-Impact-Full-Summary.pdf.

Höchstädter, A.K. \& Scheck, B. (2015). What's in a name: An analysis of impact investing understanding by academics and practitioners. Journal of Business Ethics 132(2): 449-475.

IRIS, (2015). Getting started with the IRIS. (Erişim tarihi: 18.10.2018) https://iris.thegiin.org/guide/getting-started-guide/summary.

O’Donohoe, N., Leijonjufvud, C., Saltuk, Y., Bugg-Levine, A. \& Brandenburg, M. (2010). Impact investment: An emerging asset class. New York: J.P. Morgan. (Erişim tarihi: 14.09.2018) http://www.compromisoytransparencia.org/upload/07/45/1. Impact Investments.pdf

SIIT. (2014a). Allocating for impact. (Erişim tarihi: 14.09.2018) http://gsgii.org/wp-content/uploads/2017/07/Asset-Allocation-WG-paper16.2.16-FINAL.pdf.

SIIT. (2014b). Impact investment: The invisible heart of markets. (Erişim tarihi: 14.09.2018) http://gsgii.org/wpcontent/uploads/2017/05/Impact-Investment-Report.pdf.

SIIT. (2014c). Measuring impact. (Erişim tarihi: 18.10.2018) https://iris.thegiin.org/research/measuring-impact-subject-paper-of-theimpact-measurement-working-group.pdf.

Social Value UK. (2016). GIIRS and SROI: What is the relationship? (Erişim tarihi: 18/10/2018) http://www.socialvalueuk.org/app/uploads/2016/03/GIIRS\%20and\%20SROI\%20(2).pdf.

SROI Network. (2012). A Guide to social return on investment. (Erişim tarihi 18.09.2018) http://www.socialvalueuk.org/app/uploads/2016/03/The\%20Guide\%20to\%20Social\%20Return\%20on\%20Investment\%202015.pdf.

UN PRI. (2016). Principles for Responsible Investment brochure. (Erişim tarihi 10.09.2018) https://www.unpri.org/download?ac=1534.

US SIF. (2016). The impact of sustainable and responsible investment. (Erişim tarihi 10.09. 2018) https://www.ussif.org/files/Publications/USSIF_ImpactofSRI FINAL.pdf.

US SIF. (2017). 2017 Annual report: US SIF and US SIF Foundation. (Erişim tarihi 10.09. 2018) https://www.ussif.org/files/Publications/2017USSIFAnnualReport online.pdf.

Weber, O. \& Duan, Y., (2012). Social Finance and Banking. Baker \& Nofsinger. (Ed.) Socially Responsible Finance and Investing içinde, 161180. New Jersey: Wiley. 